\title{
Givenness, complexity, and the Danish dative alternation
}

\author{
Johannes Kizach • Laura Winther Balling
}

Published online: 7 June 2013

(C) Psychonomic Society, Inc. 2013

\begin{abstract}
In this study, we investigated the interaction between givenness and complexity on the choice of syntactic structure, via two experiments using speeded acceptability judgments. Experiment 1 showed that for the Danish dative alternation, given-new orders are only easier to process for double-object or NP constructions, whereas PP constructions are unaffected. This replicates previous findings for the English dative alternation. Experiment 2 revealed that when a long NP precedes a short NP-a suboptimal complexity relation - the effect of givenness is neutralized, whereas givenness remains influential when the complexity relation between the NPs in the sentence is optimal. This is consistent with the view that in online parsing, the actual syntactic structure-building process is primary, whereas any higher-order computations such as discourse linking are secondary. The relative complexity of the NPs in the double-object construction directly affects the structurebuilding process, whereas the decoding of the discourse structure is a later and less crucial phenomenon, resulting in neutralization of the givenness effect in cases in which the complexity relation is suboptimal.
\end{abstract}

Keywords Context effects · Discourse processing · Language comprehension - Syntactic processing - Sentence processing

It is often assumed that, in any given sentence, entities that are already given in the discourse or context occur before those entities that are new in the discourse. However, givenness is not the only factor that determines word order

\section{J. Kizach $(\square)$}

Department of Aesthetics and Communication,

University of Aarhus, Jens Chr. Skous Vej 4,

8000 Aarhus C, Denmark

e-mail: engjk@hum.au.dk in cases in which speakers have a choice (i.e., are not constrained to a single syntactic structure). Rather, the choice of word order is the result of multiple factors (see Arnold, Wasow, Losongco, \& Ginstrom, 2000; Bresnan, Cueni, Nikitina, \& Baayen, 2007; Gries, 2003; Wasow \& Arnold, 2003), including both some version of givenness (previous mention, newness, salience, etc.) and the complexity of the phrases (weight, number of words, number of syntactic nodes, etc.), as well as nonlinguistic factors, as demonstrated by Coyle and Kaschak (2012). In this article, we investigate the roles of both givenness and complexity from a psycholinguistic perspective and, in contrast to previous studies (cf. Arnold et al., 2000; Bresnan et al., 2007; Gries, 2003; Wasow \& Arnold, 2003), also consider their interaction.

One case in which speakers have a choice of word order is the dative alternation, which is found in many languages, including English and the Scandinavian languages. The dative alternation allows speakers two different ways of ordering the theme and recipient - that is, for a prototypical double-object verb like give, the object that is given, and the person who receives that object. These are expressed either as two noun phrases (NPs; the NP construction; see Example 1) or as an NP and a prepositional phrase (PP; the PP construction; see Example 2). In the NP construction, the theme follows the recipient, whereas in the PP construction, the theme precedes the recipient:

(1) NP construction

Skolelæreren gav eleven et æble. teacher the gave pupil.the an apple

"The teacher gave the pupil an apple."

(2)

\section{PP construction}

Skolelæreren gav et æble til eleven. PP construction teacher the gave an apple to student.the

"The teacher gave an apple to the pupil."

Psycholinguistic studies of the English dative alternation (Brown, Savova, \& Gibson, 2012; Clifton \& Frazier, 2004) have demonstrated that given-new orders are read faster 
than new-given orders, but only for the NP construction, in which the recipient precedes the theme. No such reading time advantage for given-new is found in the PP construction. Interestingly, the pattern is found both when givenness/newness is established using a prior context, and when it is simply marked using definite versus indefinite articles (Brown et al., 2012; Clifton \& Frazier, 2004). This is likely to be linked to the fact that definiteness and givenness are highly correlated in English, as was demonstrated by Bresnan et al. (2007): 2,698 out of 3,704 (73\%) of the definite NPs in their data were given (data set available in the languageR package for R by Baayen, 2011).

Givenness is often defined as a binary category in which previous mention of the referent renders an element given (Arnold et al., 2000; Clifton \& Frazier, 2004; Wasow, 2002, p. 68). Others also consider an element to be given (or partially given) if it is activated through mention of related words (thus, engine could be considered given if car were mentioned), and thereby they expand givenness to more of a graded notion instead of a binary category (Givon, 1988; Gries, 2003; Prince, 1992; Sgall, Hajičová \& Panevová, 1986). The evidence for the relevance of givenness (even in the simplest definition) on the choice of word order is overwhelming (see, e.g., Wasow \& Arnold, 2003, and the references cited therein), and, specifically for the English dative alternation, several studies have shown that givenness is a key factor (Arnold et al., 2000; Bresnan et al., 2007; Bresnan \& Hay, 2008; Brown et al., 2012; Clifton \& Frazier, 2004).

The fact that the given-new advantage is only found for the NP construction led Brown et al. (2012) to conclude that the NP construction is dedicated to a particular informationstructural context, in which the recipient is given, whereas the theme is a new discourse referent. The idea that certain constructions have specific information-structural functions is not new: In Danish, so-called cleft sentences have been analyzed as focus constructions (Togeby, 2003, p. 173), and for Hungarian, Kiss (2007) argued for a designated topic position. It is conceivable that the NP construction in English is another example, and we investigate in this article whether something similar holds for Danish.

The second factor that we are interested in here is complexity. Complexity may be defined in various ways, but it does not seem to matter much whether it is measured in terms of syntactic nodes, syllables, or words (Szmrecsányi, 2004; Wasow, 1997). In this article, we will use the number of words to quantify complexity. In several studies of English and other languages (including Danish), a correlation has been demonstrated between word order and complexity (Arnold et al., 2000; Bresnan et al., 2007; Gries, 2003; Hawkins 1994, 1998; Kizach, 2012). Simplifying somewhat, the observation is that if two (or more) elements can be ordered in different ways, there is a strong tendency to choose the order with the least complex element before the more complex one. Specifically for the English dative alternation, both corpus and psycholinguistic studies have demonstrated the relevance of complexity (Arnold et al., 2000; Bresnan et al., 2007; Hawkins, 1994; Wasow \& Arnold, 2003).

Thus, the dative alternation provides an opportunity to examine how givenness and complexity interact in determining word order: One possibility is that both factors are equal and cancel each other out in the case of diverging preferences; another possibility is that one of the factors is primary, in which case the effect of the secondary factor should be neutralized when they diverge. Little attention has been paid to the relative strengths of these factors, but a corpus study (Hawkins, 2000) of the interaction between complexity and semantic connectedness (the degree of semantic dependency between a verb and a preposition) pointed toward a hierarchical ordering. Hawkins investigated the order of postverbal PPs and concluded that complexity overrides the factor Semantic Connectedness. When the PPs have equal complexity, semantic connectedness predicts their order quite well, but when they differ in complexity, complexity alone predicts the order (Hawkins, 2000). The idea is that the actual structure-building process is primary, and any other factor (such as semantic connectedness) is only influential when the structure is optimal with respect to complexity - that is, when longer, more complex constituents follow shorter, less complex ones.

A somewhat different result was reached in a corpus study by Weichmann and Lohmann (2013), in which complexity was compared with semantic connectedness. Their results showed that complexity has greater data coverage than semantic connectedness, making correct predictions for $78 \%$ of cases, versus $30 \%$ for semantic connectedness. However, semantic connectedness is stronger when the two factors differ; in 69 out of 99 cases in which the two factors gave conflicting predictions, semantic connectedness won (A. Lohmann, personal communication, October 29, 2012). Interestingly, when givenness is added to the model, the overall precision is only raised slightly (from $76.8 \%$ to $78.7 \%$ correct predictions), suggesting that this factor is weaker than both complexity and semantic connectedness.

In this article, we present the results of two experiments designed to investigate the possible effects of givenness and complexity for the Danish dative alternation, which to our knowledge has not previously been the subject of psycholinguistic studies. The first question that we wanted to address was: Do we see the same pattern in Danish as in English? Leaving the details aside for now, Experiment 1 showed that Danish is exactly like English: The NP construction is affected by givenness, whereas the PP construction is not.

The second question was how complexity interacts with givenness. On the basis of Hawkins's (2000) corpus study, 
we predicted that any givenness effect would be neutralized when the relative complexity of the two constituents was suboptimal - that is, if a given-new order resulted in a more complex constituent being placed before a less complex one. Experiment 2 was designed to test this prediction. Again leaving details aside, the experiment showed that when complexity disfavors an order, no givenness effect is observed. When, by contrast, the order was optimal with regard to complexity, we observed a givenness effect that was similar to that observed in Experiment 1 (i.e., the given-new order facilitated processing, as compared with the new-given order).

\section{Experiment 1}

\section{Method}

Participants The participants were 30 students or former students at the University of Aarhus (21 females, nine males). Their ages varied from 20 to 46 years (mean age 26.7), and all were native speakers of Danish.

Materials Fourteen sets of sentences were constructed using the ten most frequent dative-alternating verbs (on the basis of a search in KorpusDK, available at www.ordnet.dk/ korpusdk/). All of the sentences had unmodified nouns as the theme and recipient. Each sentence occurred in each construction type (NP and PP) and with each order of definite and indefinite, with definite NPs being understood as given and indefinite as new. An example of one of these 14 sets can be seen in Table 1 .

Table 1 One of the 14 quadruples used as stimuli in Experiment 1

\begin{tabular}{|c|c|c|c|}
\hline A. & $\begin{array}{l}\text { Direktør Clausen lovede } \\
\text { manden et arbejde } \\
\text { president Clausen promised } \\
\text { man.the a job } \\
\text { "President Clausen promised } \\
\text { the man a job." }\end{array}$ & NP construction & Def-indef \\
\hline B. & $\begin{array}{l}\text { Direktør Clausen lovede } \\
\text { en mand arbejdet } \\
\text { "President Clausen promised } \\
\text { a man the job." }\end{array}$ & & Indef-def \\
\hline C. & $\begin{array}{l}\text { Direktør Clausen lovede } \\
\text { arbejdet til en mand } \\
\text { "President Clausen promised } \\
\text { the job to a man." }\end{array}$ & PP construction & Def-indef \\
\hline D. & $\begin{array}{l}\text { Direktør Clausen lovede } \\
\text { et arbejde til manden } \\
\text { "President Clausen promised } \\
\text { a job to the man." }\end{array}$ & & Indef-def \\
\hline
\end{tabular}

Apart from the 56 target sentences, the materials also included 64 fillers, 40 of which were sentences structurally similar to the target sentences, but with semantic, syntactic, or orthographic mistakes. The remaining 24 sentences were materials for an unrelated study.

Task and procedure The sentences appeared one at a time (in pseudorandomized order) in the middle of the screen following a plus sign. The participants were instructed to accept or reject each sentence by pressing either a red X (rejection) or a green $\checkmark$ (acceptance), both marked on the keyboard, as fast as they could without losing their precision - that is, a speeded acceptability judgment task. We encouraged the participants to rely on their intuitions in judging the sentences. In the middle of the session a pause was inserted, after which the participants pressed the space bar to continue. A training session with four items was run first to familiarize participants with the task. Stimulus presentation was done using DMDX (Forster \& Forster, 2003), and reaction times (RTs) and responses were recorded.

Statistical model A linear mixed-effects regression model was fitted to the dependent variable RT (logarithmically transformed in order to reduce skewness) using the R software environment (R Development Core Team, 2009) and the lme4 package for R (Bates, Maechler, \& Bolker, 2011). The dependent variable was $\log \mathrm{RT}$, and the predictors a mixture of factors and continuous variables: Construction type (NP or PP), givenness (given-new or new-given), order of presentation, distance to the last use of the same combination of given-new and NP-PP, and number of previous uses of that combination. The model also included random intercepts for participants and items (supported by likelihood ratio tests; no other random effects were justified). The model was fitted by adding the variables one at a time, starting with the most control-oriented variables and ending with the central interaction between construction type and givenness. Nonsignificant variables were removed from the model.

\section{Results}

The results of Experiment 1 are shown in Fig. 1 and confirm the pattern observed for English by Clifton and Frazier (2004) and Brown et al. (2012): Participants responded significantly faster to NP constructions with a given-new order than to NP constructions with a new-given order $(p=.0008)$. The pattern for PP constructions was significantly different, as indicated by the significant interaction term in the final line of Table $2(p=.0004)$. The model summarized in Table 2 does not provide a simple comparison between given-new and new-given orders for PP 


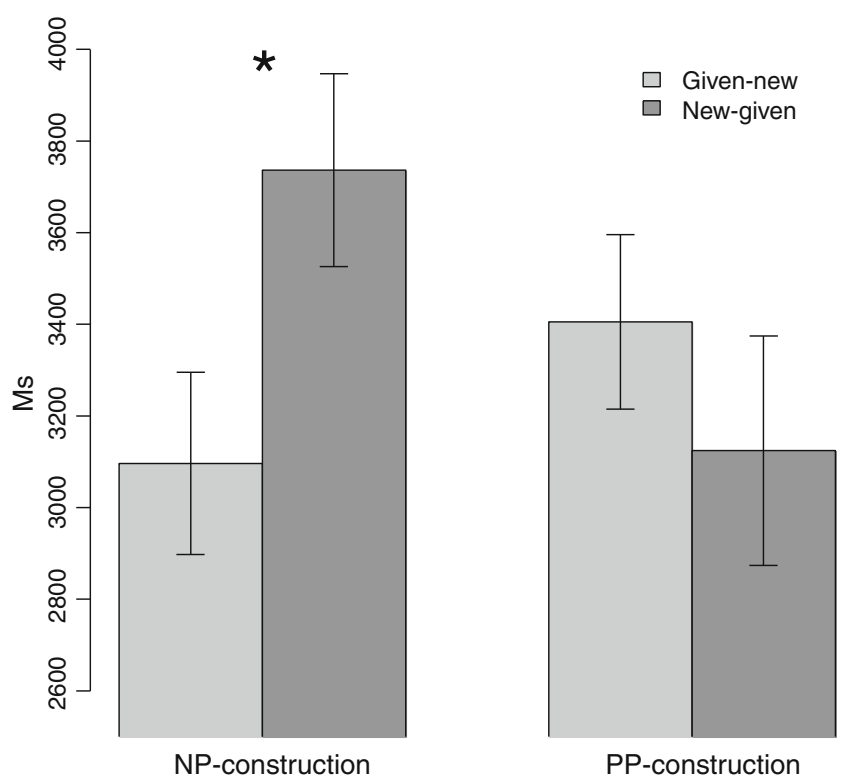

Fig. 1 Partial-effects plot showing the model's predicted reaction times for the NP and PP constructions with given-new and new-given orders. Error bars show $\pm 1 S E$. The star $\left(^{*}\right)$ indicates a significant difference (at the $.05 \alpha$ level).

constructions, but if we changed the reference level for constituent, we found that the effect of givenness for PP constructions went in the opposite direction than that for NPs, with new-given being processed faster than givennew orders, but this effect did not quite reach significance $(p=.0818)$. Considering effect sizes, for NPs we observed a 600-ms advantage for given-new over new-given constructions, whereas for PPs the difference went in the opposite direction, with an almost 300-ms advantage for new-given; this result, however, did not reach significance.

A reviewer suggested that this (marginally significant) preference for new-given order in the PP construction could be a side effect of a general preference for animate phrases to be definite, since the recipient is definite only in the newgiven PP constructions (and indefinite in the given-new orders). If this is correct, the pattern should be altered if both the recipient and the theme were inanimate (because then there would be no preference for animate second NPs to be definite any more). Fortunately, the stimuli contained four quadruples with inanimate themes and inanimate recipients (institut "institute," bank "bank," organisation "organization," and landsby "village"), and these reflected the same pattern as the data in general, with longer RTs for new-given NP constructions and given-new PP constructions. The pattern could therefore not be caused by a preference for animates to be definite.

In addition to this central interaction between givenness and construction type, we observed a significant effect of the previous RT, indicating that fast responses were likely to be followed by fast responses, and slow responses by slow responses. This effect looks minuscule in the model, but this is because the scale for previous RT is large, ranging from approximately $-3,500 \mathrm{~ms}$ (below the participants' mean RT) to over 9,700 ms (above the participants' mean RT); when we compared the RTs predicted by the model for the lowest values of previous RT and those predicted for the highest values, we found a difference of some 1,200 ms. The previous RT was normalized for the participants' mean RT on the advice of a reviewer, to avoid potentially harmful correlations with the participants' random intercept. However, the difference to a model using raw previous RT was minimal, so this step might not be necessary in future studies, and we did not perform the same normalization in the analysis of Experiment 2.

Finally, we found an effect of repetition, showing that participants became faster in direct proportion to the number of times that they had seen the particular structure before. However, no effect was apparent of the distance to the previous occurrence of the same structure, and this variable

Table 2 Summary of the mixed-effects model for reaction times (RTs) as a function of construction type, definiteness, structure repetition, and previous RT

\begin{tabular}{lccccc}
\hline & Estimate & MCMC Mean Estimate & HPD95 Lower & HPD95 Upper & $p$ (MCMC) \\
\hline Intercept & 8.0376 & 8.0366 & 7.9316 & 8.1399 & .0001 \\
Structure repetition & -0.0097 & -0.0097 & -0.0136 & -0.0055 & .0001 \\
Previous RT (normalized) & $<0.0001$ & $<0.0001$ & $<0.0001$ & $<0.0001$ & .0001 \\
Givenness:NewGiven & 0.1879 & 0.1879 & 0.0876 & 0.2887 \\
Constituent:PP & 0.0952 & 0.0964 & 0.0009 & 0.1961 & .0008 \\
Givenness:NewGiven*Constituent:PP & -0.2741 & -0.2744 & -0.4236 & -0.1469 & .0004 \\
\hline
\end{tabular}

The model also included random intercepts for participants ( $S D$ estimated at 0.2550$)$ and items ( $S D$ estimated at 0.1306$)$. The residual standard deviation was estimated at 0.3085 . The table shows the name of each predictor in the first column and its estimated effect size in the second column. The remaining columns are based on 10,000 Markov-chain Monte Carlo (MCMC) samples that were run on the basis of the model and the data; parameters based on such MCMC sampling provide superior accuracy, relative to $p$ values and confidence intervals based on the $t$ distribution (Baayen, Davidson, \& Bates, 2008). HPD95 indicates higher-posterior-density intervals, or credible intervals that are similar to the confidence intervals of standard tests. 
was removed from the final model. The structure-priming effect is consistent with current research in the field of syntactic priming, which has shown that even exposure to a single structure results in measurable priming effects (see, e.g., Branigan, 2007; Christensen, Kizach, \& Nyvad, 2013; Luka \& Barsalou, 2005; Snyder, 2000; Sprouse, 2007).

To investigate whether the fixed effects actually explained any variance relative to a model with just random effects, Akaike weight comparisons were performed. A reduced regression model with no fixed effects was computed, and using a function in the MuMIn package for R (Bartoń, 2009) to perform the Akaike weight comparisons, we compared the reduced model to our final model. Akaike weights can be straightforwardly interpreted as conditional probabilities for each model on a scale from 1, representing the highest probability, to 0 , representing the lowest probability (Wagenmakers $\&$ Farrell, 2004), and the results showed that the final model was the more probable one (see Table 3): The weight column shows a clear preference for the final model (weight 1 ) over the reduced model (weight 0 ).

The model reported in Table 2 is based on the participants' RTs on trials on which they responded correctly. We also analyzed the error data, in a parallel model using the binary variable correct/error as a dependent variable. The error rates are shown by construction and givenness condition in Table 4 . This model confirms the overall picture seen in the RT analysis: For NPs, more errors occurred when the order was newgiven than when it was given-new. The error analysis also showed a significant interaction between constituent and givenness, parallel to the interaction in the RT analysis. In addition, when we re-leveled the Constituent factor, we found that the advantage for new-given over given-new for the PP structures reached significance in the error analysis; in short, the error analysis showed a full reversal of the givenness effect from NPs (significant advantage for given-new) to PPs (significant advantage for new-given). Unsurprisingly, given the few error responses and the binary nature of the error variable, the previous RT and structure repetition variables did not reach significance in the error analysis.

\section{Discussion}

Experiment 1 was primarily run to investigate whether Danish shows a pattern similar to that observed in English,

which is clearly the case: Only NP constructions show givenness effects, with a preference for the given-new order. This lends support to the suggestion by Brown et al. (2012) that the NP construction is dedicated to a specific discourse structure, in which the theme is new and the recipient is given. The PP construction, on the other hand, seems not to be subject to such a constraint. We did observe a tendency for faster responses to the new-given order in the PP construction, which could indicate that the PP construction may not be completely neutral with respect to givenness, but this tendency was not quite significant. Clifton and Frazier (2004) reported the same tendency for English, but as in our results, the preference for the newgiven order in the PP construction did not reach significance. It is an interesting fact that the dedication of the NP construction to a specific information structure is general across two different (albeit related) languages.

In Experiment 1, givenness was equated with definiteness because of the strong correlation between them (Bresnan et al., 2007) and because Brown et al. (2012) and Clifton and Frazier (2004) both demonstrated that the same pattern was found, irrespective of whether givenness was equated with definiteness or established briefly in the preceding context. Nevertheless, definiteness is, of course, not exactly the same as givenness, and in Experiment 2 we therefore established the givenness of one of the arguments through mention of the referent in a prior context, following the method used in Arnold et al. (2000, p. 30) and in Clifton and Frazier (2004, p. 890).

In Experiment 1, the complexity of the two NPs was the same in order, as a first step, to investigate the isolated effect of givenness and avoid any complexity effects. Following Hawkins (1994), we measured complexity as the number of words in a phrase, with the exception that we counted the definite article as a word even when it was a suffix attached to the noun. The reason is that the Danish definite article differs from the indefinite article only in the position in which it appears (cf. Examples 3 and 4). When a prenominal adjective is added, the definite article is no longer suffixed, but is instead expressed as a prenominal determiner (as in Example 5).

(3) En bil a car

(4) Bilen carthe (indefinite article + noun)

(noun + definite article)

Table 3 Experiment 1: Models, intercepts, fixed effects in the models (all or none), degrees of freedom, corrected Akaike information criteria (AICc), AICc difference (Delta), and AICc weight

\begin{tabular}{llllllll}
\hline & $($ Int $)$ & Fixed Effects & $d f$ & $\operatorname{logLik}$ & AICc & Delta & Weight \\
\hline Final model & 7.926 & all & 9 & -471.155 & 960.4 & 0.00 \\
Reduced model & 8.035 & none & 4 & -519.109 & $1,046.2$ & 85.81 & 0 \\
\hline
\end{tabular}


Table 4 Proportions of correct and error responses (in percentages) in Experiment 1, by construction and givenness

\begin{tabular}{llllll}
\hline & $\mathrm{NP}$ & & $\mathrm{PP}$ \\
\cline { 2 - 3 } \cline { 5 - 6 } & Given-New & New-Given & & Given-New & New-Given \\
\hline Correct & .95 & .84 & .95 & .99 \\
Error & .05 & .16 & .05 & .01 \\
\hline
\end{tabular}

(5) Den store bil the big car

If the definite article were not counted as a word when it appeared as a suffix, we would have to say that the definite article only added to the complexity of the phrase in certain syntactic environments (when it co-occurred with an adjective) and not in others. We would rather say that the article added to the overall complexity of a phrase whenever it was present, and therefore counted it as a word in all cases.

Another way of defining complexity is through the number of syntactic nodes, instead of the number of words (Hawkins, 1994; Kizach, 2012), but two studies have demonstrated that the predictions are the same, no matter how complexity is defined (Szmrecsányi, 2004; Wasow, 1997). Interestingly, the number of syntactic nodes is the same in Examples 3 and 4, assuming a structure with an NP and a determiner phrase (DP) as in Vikner (1995), so this is one of the few cases in which the syntactic definition of complexity actually differs from the simple length measure. Here we took the syntactic definition of complexity into account by counting a noun plus a definite article suffix as two words.

In Experiment 2, we examined the NP construction and manipulated the complexity of the recipient and theme arguments to investigate how complexity and givenness interact. ${ }^{1}$ Three levels of complexity differences were tested: no difference, a small difference (two words), and a large difference (five words). The cases with no complexity difference were thus structurally identical to the materials used in Experiment 1, but now givenness was established via a short preceding context.

Following Hawkins (2000), we hypothesized that complexity is a more important factor than givenness. This is based on the reasoning that recognizing the syntactic structure of the sentence, which is aided by an appropriate complexity relation between the two NPs, is more fundamental than coding of discourse status through the order of given and new constituents. We therefore predicted that the givenness effect observed in Experiment 1 (faster RTs for

\footnotetext{
${ }^{1} \mathrm{PP}$ constructions were not included because we were interested in the interaction between complexity and givenness, and the PP constructions showed no significant givenness effect in Experiment 1.
}

the given-new order than for the new-given order) would be neutralized when the complexity difference went the wrong way - that is, when a longer NP preceded a shorter $\mathrm{NP}$ - and would be replicated when the complexity effect was neutral or favored a certain order.

\section{Experiment 2}

Method

Participants The 40 participants were students from the University of Aarhus and people from the area around the university. All were native speakers of Danish, and none had participated in Experiment 1. Their ages varied from 20 to 74 years (mean age 33.3). Because of the relatively large age span, we tested age as a predictor in the model; however, this was not significant and is not included in the final model or discussed further.

Materials Eight of the high-frequency verbs employed in Experiment 1 were used in Experiment 2 to construct a novel set of sentences. The sentences were NP constructions with varying complexity differences, and all sentences appeared in two versions: one with definite-indefinite order, and one with indefinite-definite order. The complexity relation between the two NPs was such that they did not differ in length, differed in length by two words, or differed in length by five words. Half of the sentences with complexity differences had the preferred order, less complex before more complex (plus2 and plus5), and the other half had the opposite order, more complex before less complex (minus2 and minus5). Thus, the paradigm involved the crossed factors complexity and givenness: five types of different relative complexities, all appearing in a given-new and a new-given order (see the examples in Table 5). Apart from the 80 target sentences, the experiment included 82 filler sentences ( 24 sentences for an unrelated study, and 58 fillers with syntactic, semantic, or orthographic mistakes).

Task and procedure Each target sentence was preceded by a short context establishing the definite NP as being given. The contexts appeared with yellow letters in order to separate them from the target sentences, which were written with white letters. Below the context sentence, a line of hyphens indicated where the target sentence would appear. The target sentence appeared after the participant had read the context and pressed the space bar (see Sentences 6 and 7 below for examples of a context plus its target sentence). The participants were asked to judge each sentence as being acceptable or not acceptable by pressing a key on the keyboard. The task was thus identical to the one used in Experiment 1, except that givenness was established via a context. 
Table 5 Examples of the stimuli used in Experiment 2

\begin{tabular}{|c|c|c|c|}
\hline A. & $\begin{array}{l}\text { Moster Marie gav drengen en bolle. } \\
\text { "Aunt Mary handed the boy a bun." }\end{array}$ & Neutral (No complexity difference) & Given-new \\
\hline B. & $\begin{array}{l}\text { Moster Marie gav en dreng bollen. } \\
\text { "Aunt Mary handed a boy the bun." }\end{array}$ & & New-given \\
\hline C. & $\begin{array}{l}\text { Sekretaren sendte læreren en stor aske chokolade. } \\
\text { "The secretary sent the teacher a big box of chocolates." }\end{array}$ & Plus2 (NP1 < NP2 by 2 words) & Given-new \\
\hline D. & $\begin{array}{l}\text { Sekretæren sendte en lærer den store æske chokolade. } \\
\text { "The secretary sent a teacher the big box of chocolates." }\end{array}$ & & New-given \\
\hline E. & $\begin{array}{l}\text { Teaterdirektøren lovede den usædvanligt flittige lydmand en billet. } \\
\text { "The theatre manager promised the remarkably hard-working soundman a ticket." }\end{array}$ & Minus2 (NP1 > NP2 by 2 words) & Given-new \\
\hline F. & $\begin{array}{l}\text { Teaterdirektøren lovede en usadvanligt flittig lydmand billetten. } \\
\text { "The theatre manager promised a remarkably hard-working soundman the ticket." }\end{array}$ & & New-given \\
\hline G. & $\begin{array}{l}\text { En ekspedient rakte pigen en dyr kjole med perler og lyserødt tyl. } \\
\text { "A shop assistant handed the girl an expensive dress with pearls and pink tulle." }\end{array}$ & Plus5 (NP1 < NP2 by 5 words) & Given-new \\
\hline H. & $\begin{array}{l}\text { En ekspedient rakte en pige den dyre kjole med perler og lyserødt tyl. } \\
\text { "A shop assistant handed a girl the expensive dress with pearls and pink tulle." }\end{array}$ & & New-given \\
\hline I. & $\begin{array}{l}\text { Præsten rakte den ældre kvinde med sort tøj og sko en bog. } \\
\text { "The priest handed the elderly woman in black clothes and shoes a book." }\end{array}$ & Minus5 (NP1 > NP2 by 5 words) & Given-new \\
\hline J. & $\begin{array}{l}\text { Præsten rakte en aldre kvinde med sort toj og sko bogen. } \\
\text { "The priest handed an elderly woman in black clothes and shoes the book." }\end{array}$ & & New-given \\
\hline
\end{tabular}

(6) a. En venlig og en uvenlig ung mand henvendte sig A friendly and an unfriendly young man enquire self samtidigt i en bar. simultaneously in a bar

"At a bar a friendly and an unfriendly young man called out simultaneously."

b. Bartenderen rakte den venlige unge mand en flaske. Bartender.the handed the friendly young man a bottle "The bartender handed the friendly young man a bottle."

In four of the ten conditions (i.e., plus2 new-given, minus2 given-new, plus5 new-given, and minus5 given-new), the NP that was classified as given was either mentioned in full in the context sentence, as in Example 6, or partially mentioned, as in Example 7.

(7) a. Den fineste plads i teateret stod ofte tom fordi The nicest seat in theater.the stood often empty because

dronningen sjældent kom.

queen.the rarely came

"The nicest seat in the theater was often empty, because the Queen rarely came."

b. Teaterdirektøren tilbød en tilskuer den fine plads med udsigt

Theater.director.the offered a spectator the nice seat with view

til orkesteret.

to orchestra.the

"The director of the theater offered a guest the nice seat with a view to the orchestra."
In Example 7, we consider the NP "the nice seat with a view to the orchestra" to be given, because the referent of the NP (i.e., the seat) was mentioned in the preceding context, although the postmodifying PP "with a view to the orchestra" was not. We thus followed the definitions of givenness found in Arnold et al. (2000, p. 30), Gries (2003, pp. 19-20), Prince (1992), and Wasow (2002, p. 68), in which the crucial difference between new and given was precisely previous mention of the referent. The givenness of all NPs classified as given was further supported by them occurring in the definite form, whereas all new NPs were indefinite, which in itself indicates novelty (cf. Schwarzschild 1999, p. 154)

\section{Results}

The results of the experiment were analyzed in the same way as the results of Experiment 1 . The final model is summarized in Table 6.

Our hypothesis was that the effect of complexity-the length and complexity differences between the NPs-would dominate the effect of givenness. This means that what we were interested in for this model was not an interaction effect, but the effects of givenness at the different levels of complexity/length difference, and we coded the effects accordingly. What is important in Table 6 is therefore the last five lines, which show the givenness effects at each of the levels of length difference. This shows clearly that the given-new order was preferred when the complexities of the two NPs were identical or when the second NP was longer than the first (length differences of plus2 and 
Table 6 Summary of the mixed-effects model of reaction times (RTs) in Experiment 2, as a function of givenness, length difference, trial, and the previous RT

\begin{tabular}{|c|c|c|c|c|c|}
\hline & Estimate & MCMC Mean & HPD95 Lower & HPD95 Upper & $p(\mathrm{MCMC})$ \\
\hline Intercept & 7.9397 & 7.9351 & 7.8170 & 8.0549 & .0001 \\
\hline Trial number & -0.0025 & -0.0025 & -0.0028 & -0.0022 & .0001 \\
\hline Previous RT & $<0.0001$ & $<0.0001$ & $<0.0001$ & $<0.0001$ & .0001 \\
\hline LengthDifference:Minus2 & 0.3727 & 0.3722 & 0.2512 & 0.4966 & .0001 \\
\hline LengthDifference:Minus5 & 0.6351 & 0.6347 & 0.5116 & 0.7524 & .0001 \\
\hline LengthDifference:Plus2 & 0.2603 & 0.2595 & 0.1285 & 0.3820 & .0001 \\
\hline LengthDifference:Plus5 & 0.4875 & 0.4870 & 0.3658 & 0.6154 & .0001 \\
\hline LengthDifference: 0 * Givenness:NewGiven & 0.1311 & 0.1306 & 0.0159 & 0.2518 & .0308 \\
\hline LengthDifference:Minus2 * Givenness:NewGiven & -0.0151 & -0.0151 & -0.1365 & 0.1135 & .8120 \\
\hline LengthDifference:Minus5 * Givenness:NewGiven & -0.0452 & -0.0454 & -0.1680 & 0.0849 & .4754 \\
\hline LengthDifference:Plus2 * Givenness:NewGiven & 0.1354 & 0.1369 & 0.0028 & 0.2737 & .0484 \\
\hline LengthDifference:Plus $5 *$ Givenness:NewGiven & 0.1516 & 0.1515 & 0.0168 & 0.2844 & .0254 \\
\hline
\end{tabular}

The model also included random intercepts for participants ( $S D$ estimated at 0.2939$)$ and items ( $S D$ estimated at 0.1114$)$. The residual standard error was estimated at 0.3530 .

plus5) - that is, when the ordering was in accordance with the preferences imposed by the factor Complexity. The line "LengthDifference:0 * Givenness:NewGiven" indicates that in the neutral condition, in which the length difference was 0 , new-given constructions were read more slowly than given-new constructions $(p=.0310)$. The lines "LengthDifference:Plus2 * Givenness:NewGiven" and "LengthDifference:Plus5 * Givenness:NewGiven" indicate that new-given was slower than given-new when the length difference was both two $(p=.0474)$ and five $(p=.0268)$ in the preferred direction. By contrast, when the first NP was more complex than the second, we found no effect of givenness ( $p=.8190$ for the length difference of two and $p=.4738$ for the length difference of five in the dispreferred direction).

This pattern of results is illustrated in Fig. 2: Each pair of dark and light gray bars represents the RT predicted by the model for a single complexity condition. In the neutral, plus2, and plus5 conditions, we see significant RTs that are between 400 and $750 \mathrm{~ms}$ lower for given-new orders (light gray) than for new-given (dark gray) orders. For the neutral condition, this is slightly lower than the approximately 600-ms difference observed for the parallel stimuli in Experiment 1, but the difference remains significant for all conditions not dispreferred by the complexity constraint. By contrast, the bars for minus 2 and minus 5 - that is, the cases in which the longest NP came first- show no difference.

In sum, when the preference for less complex before more complex order was violated (minus2 and minus5), givenness had no effect on RTs. When the order was less complex before more complex (or neutral), the given-new order was preferred.

In addition to the central interaction between complexity and givenness, we observed effects of the control variables trial and previous RT. As in Experiment 1, longer RTs on previous trials indicated longer RTs on the current trial. Additionally, the model showed an effect of trial, with faster RTs occurring later in the experiment, indicating a certain habituation to the task. Since only one kind of structure was used in this experiment, this may represent the same type of priming observed in the effect of repetition of structures in Experiment 1.

As we discussed above, we defined given NPs as those whose referents had been mentioned in the preceding

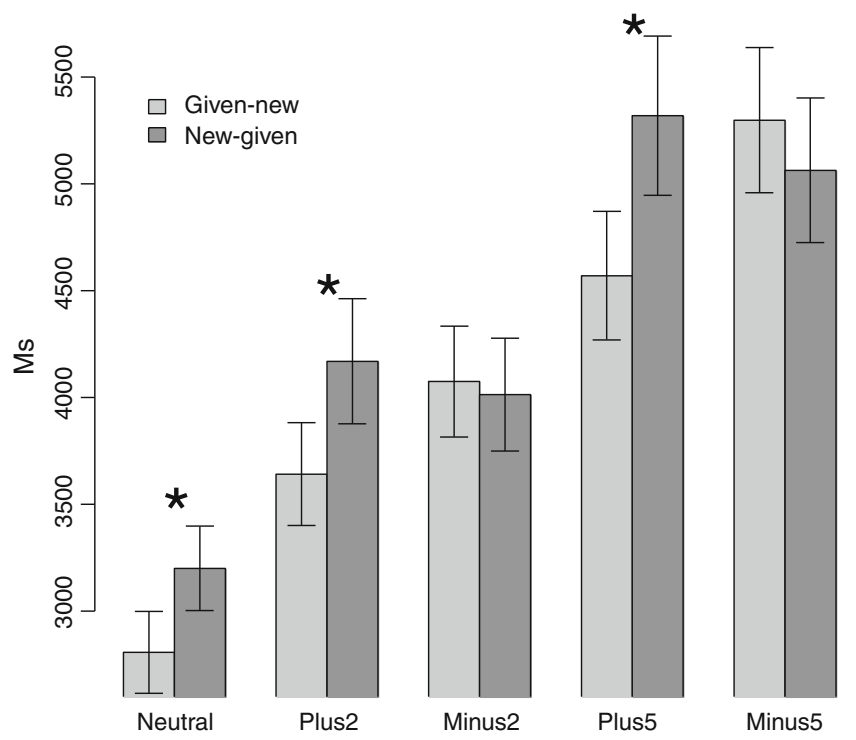

Fig. 2 Partial-effects plot showing the model's predicted reaction times for the five conditions (neutral, plus2, minus2, plus5, and minus5) in the given-new and new-given orders. Error bars show $\pm 1 S E$. Stars $(*)$ indicate significant differences (at the $.05 \alpha$ level). 
context, following the general consensus in the literature. In four of our conditions, the given NPs were not necessarily mentioned in full in the context (though the referent was unambiguously identified); in particular, this was necessary for the plus5 new-given and minus5 given-new conditions, in which the context sentences would become highly unnatural if the long, given NPs were mentioned in full. In the plus2 new-given and minus2 given-new conditions, we had both sentences with full and sentences with partial mention of the given NP in the context, and could therefore investigate whether this had an effect. We did so by comparing partial and full mention in the context in a separate mixed model for each of the two relevant categories. We found no significant effects of partial versus full mention in either analysis ( $p=.84$ for plus2 new-given, $p=.28$ for minus 2 given-new); on the basis of this nonsignificant result, we concluded that it was unlikely that the issue of partial versus full mention of the given NP affected our results more generally.

We again used Akaike weight comparisons to compare a reduced model (with random effects only) to our final model, in order to see whether the fixed effects would increase the explained variance. As in Experiment 1, this was clearly the case, as can be seen in Table 7, where the final model has a weight of 1 (maximum probability), whereas the reduced model has a weight of 0 (minimum probability).

As in the analysis of Experiment 1, the model reported in Table 6 includes only trials on which the participant responded correctly that the sentence was acceptable. In addition, we ran a logistic regression model analyzing the binary response variable correctness, on the basis of the error rates; these results are summarized in Table 8 . Here, we see fewer significant effects than in the RT analysis, as we would expect. The most relevant significant effects were a givenness effect for length 0 - that is, when there was no length difference - such that new-given orders were more error-prone than given-new orders, in line with the RT analysis and the results of Experiment 1 . The givenness effect did not reach significance at any other level. In addition, we see a somewhat interesting length effect: Significantly more errors occurred in both of the minus conditions - that is, minus 2 and minus 5 - than in the neutral-length condition, whereas no difference emerged between the neutral-length and plus conditions. Apparently, the sentences that are dispreferred due to complexity are more error-prone than those that are not. Finally, we see a small effect of trial, with fewer errors occurring later in the experiment, an indication of some training effect, similar to what was indicated by the RT analysis.

\section{Discussion}

The aim of Experiment 2 was to investigate the relation between givenness and complexity, and a central question was whether the two factors would be equally influential or would be hierarchically ordered. The results showed a clear given-new preference for the NPs when the complexity preference was not violated, confirming the results of Experiment 1 and of previous studies of the English dative alternation. In contrast, the givenness effect was neutralized when the order of NPs was suboptimal with respect to complexity: When a longer NP preceded a shorter NP, the preference for given-new orders disappeared. A possible interpretation of this neutralization effect is that complexity is more fundamental for comprehension than givenness. This is discussed further in the General Discussion below.

A comparison of Experiments 1 and 2 indicates that context did not play a decisive role for the reading of our target sentences: The same pattern of given-new preferences was found for the NP constructions in Experiment 1, which occurred without a context, and those in Experiment 2, which occurred with contexts. This is similar to the results of Clifton and Frazier (2004), who found no effect of context on givenness. The fact that the same pattern emerged in both experiments suggests that context is less important than might be expected, in the sense that definiteness alone appears to be processed as indicating givenness, in the absence of contextual clues suggesting otherwise. We did not, however, use contradicting context and articles, so it remains an open question whether syntactic or contextual cues to information structure are primary.

\section{General discussion}

Givenness and complexity are both factors that have been demonstrated to influence word order in several different constructions in several different languages. Experiment 1

Table 7 Experiment 2: Models, intercepts, fixed effects in the models (all or none), degrees of freedom, corrected Akaike information criteria (AICc), AICc difference (Delta), and AICc weight

\begin{tabular}{llllllrr}
\hline & (Int) & Fixed Effects & $d f$ & logLik & AICc & Delta & Weight \\
\hline 1 & 7.940 & all & 15 & $-1,093.937$ & $2,218.1$ & 0.0 & 1 \\
2 & 8.163 & none & 4 & $-1,417.925$ & $2,843.9$ & 625.8 & 0 \\
\hline
\end{tabular}


Table 8 Proportion of correct and error responses (in percent) in Experiment 2 by condition

\begin{tabular}{llll}
\hline & & Correct & Error \\
\hline Neutral & Given-new & .96 & .04 \\
& New-given & .89 & .11 \\
Plus2 & Given-new & .91 & .09 \\
& New-given & .92 & .08 \\
Minus2 & Given-new & .90 & .10 \\
& New-given & .89 & .11 \\
\multirow{3}{*}{ Minus5 } & Given-new & .95 & .05 \\
& New-given & .94 & .06 \\
& Given-new & .83 & .18 \\
& New-given & .76 & .24 \\
\hline
\end{tabular}

investigated givenness effects in Danish and replicated the pattern found in English (Brown et al., 2012; Clifton \& Frazier, 2004): Givenness matters for NP constructions only, such that given-new orders are processed significantly faster than new-given orders. For PP constructions, there is a marginally significant tendency in the opposite direction: New-given orders are processed faster. This supports the idea formulated by Brown et al. (2012) that the NP construction is tied to a specific information structure - namely, one in which the first NP is given and the second is new-whereas the PP construction presumably has no such restriction. Experiment 2 showed that the influence of givenness is not just limited to NP constructions, but is further limited to cases in which the complexity preference is not violated - that is, to cases in which the first NP is less complex than or equally complex as the second NP.

Although several components are potentially involved in the speeded acceptability judgment task, we take it that RTs at least to some extent reflect relative parsing effort; so, for instance, the given-new order of the plus 2 condition in Experiment 2 was easier to parse than the corresponding new-given order, as could be seen by the lower RT. For this reason, we offer a parsing account of why complexity dominates givenness. However, other elements of the acceptability judgment task should also be considered, most importantly the idea that RTs in such a task reflect production constraints (cf. Pickering \& Garrod, 2007).

Production has been argued to partially or totally determine where and when comprehension difficulties arise (Hawkins, 1994, 2004; Macdonald, 2012; Pickering \& Garrod, 2007). Pickering and Garrod (2007, p. 106) suggested that readers/listeners use covert production to predict upcoming words in contexts where they are highly predictable. Thus, in a sentence like please, pass me the salt and , we can predict the word pepper. However, for words that are not highly predictable, the benefit of expecting specific words is extremely small, because the transitional (or cloze) probabilities are very small (in fact, they are close to zero), and little evidence suggests an effect on RTs (Clifton \& Staub, 2008, p. 244; see, however, Smith \& Levy, in press). For the ditransitive verbs in our experiment, it is conceivable that there was an expectation of two arguments, but we have no way of determining whether this was a parsing phenomenon, as argued by Hawkins (1994), or an effect of covert production. Also, it is not clear how such an expectation would influence our results.

Macdonald (2012) presented the production-distribution-comprehension hypothesis (PDC), according to which comprehension is completely determined by distribution patterns, which are in turn determined by production principles. The PDC would account for our results in the following way: First, the production principle easy first (Macdonald, 2012, p. 17) guarantees that short-before-long and given-new orders are produced more often than the opposites. The short-before-long order is preferred in production because the shorter phrase is easier to produce, and so is produced first. Given-new is also preferred in production (again because of easy first), because the given phrase is more salient, and therefore easier to recall from memory, and thus is produced first. Second, the preference in production guarantees that short-before-long and given-new orders are the most frequent ones. Finally, listeners and readers are faster when processing these orders, due to their higher frequency. The PDC thus ultimately derives all comprehension effects from frequency patterns, which are derived from production principles.

According to the PDC, the preference that we observed for given-new over new-given in the neutral, plus2, and plus5 conditions simply reflects the (possible) higher frequency of this pattern. The lack of a preference for givennew over new-given in the minus 2 and minus 5 conditions should then reflect that both are equally infrequent (whether a length difference of two words really is highly infrequent in the long-before-short order is of course an empirical question, but we leave this for future research). Crucially, even the PDC account seems to implicate a higher ranking of complexity than of givenness, because the production of a long-before-short order is avoided, even if it would result in keeping the preferred given-new order. Instead of producing an NP construction with a long-before-short and given-new order, a PP construction could be used, but then the order would be new-given, which violates the easy first production principle. Easy first never endorses long-beforeshort order, but in the PP construction, the "easy last" newgiven order is produced (and marginally preferred). In short, even under the PDC we need some explanation as to why it is better to violate givenness than complexity.

The idea that all comprehension difficulties are linked to frequency distributions is perhaps too strong a claim. A counterexample to the PDC would be any case in which low frequency does not result in comprehension difficulties, 
or in which high frequency induces difficulties, and such cases are not rare in the literature. Using event-related brain potentials, Bornkessel, Schlesewsky, and Friederici (2002) demonstrated how difficulties in the online processing of German accusative-marked objects, as compared to subjects and dative-marked objects, do not correspond to their frequency distributions, but can be predicted by syntactic distinctions. Pickering, Traxler, and Crocker (2000) reported an eyetracking experiment investigating verbs that can take either an NP object or a clausal object. Sentences with a temporary ambiguity between the NP- and the clausal-object readings were presented, and plausibility was manipulated. Realize, for instance, can take an NP or a clausal object, but clausal objects are much more frequent with this verb, but even so, Pickering et al. found an effect of plausibility with realize, suggesting that the low-frequency NP-object analysis was adopted. Similarly, Pickering and Traxler (2003) showed that an effect of plausible versus implausible NP objects was found in sentences with a temporary ambiguity between an NP-object and a PP-object analysis, even when the PP analysis was the most frequent one. Finally, Kizach and Christensen (in press) showed that temporal adjunct clauses are much more frequent in iconic positions than in noniconic positions in a corpus study of Danish - that is, in production and distribution-but nevertheless, no comprehension difficulties were found for noniconic orderings in an online reading experiment. Taken together, these studies suggest that the strongest version of the PDC is untenable, and that comprehension difficulties cannot be explained solely by frequency patterns of the simple kind that the PDC operates with (cf. Newmeyer, 1998, pp. 134-136, for a discussion of frequency and syntactic constructions).

Whereas we agree that distribution patterns must derive from production, we find it unlikely that comprehension exclusively reflects these patterns. Instead, we suggest that the reason why complexity dominates givenness is that it is a more important factor during parsing. One possible reason for this dominance could be that, during online parsing, syntactic processing is attended to first (cf. Frazier, 1987; Fodor \& Inoue, 1998; Pritchett, 1992). Since complexity is directly related to the structure-building process, effects of complexity are dominant, whereas givenness is related to discourse and information structure, which are higher-order phenomena and are therefore computed later in online processing. In other words, before we can determine whether a phrase is or is not given, it first has to be constructed and integrated into the structure.

Psycholinguists do not agree whether syntactic processing is a prerequisite for all other computations, and our results also can not finally settle the question of whether syntactic operations occur temporally earlier in two-stage serial parsing. They are, however, in line with many studies that have demonstrated that syntactic cues override semantic, contextual, and pragmatic cues: Ferreira and Clifton (1986) found no effects of semantic or contextual cues in experiments involving eyetracking and self-paced reading, but only effects of the syntactic cues. Pickering and Traxler (2003) found that initial attachment decisions ignored frequency. Mitchell (1987) and van Gompel and Pickering (2001) found that even lexical co-occurrence information was initially ignored by the parser (see also Staub, 2007, for a discussion). Frazier and Clifton (1996, p. 3) expressed the privileged status of syntactic processing in the following way: "Readers and listeners can arrive at an interpretation that violates their beliefs about the message being conveyed, their feelings of plausibility or contextual felicity, and their wishes and expectations. They do not arrive at interpretations that violate grammar."

A short-before-long order aids the parser to an efficient construction of the syntactic representation, whereas a longbefore-short order delays the process. Given that the construction of the syntactic representation is a key element in comprehension, complexity must be more important than information-structural phenomena. The idea that complexity is temporally first follows from this line of thinking, but is not a necessary consequence of it.

The neutralization of givenness in long-before-short orders is reminiscent of two other neutralization cases reported for Danish. Poulsen (2008) reported that a strong acceptability contrast between sentences with and without semantic cohesion disappears when extractions out of adjuncts (considered ungrammatical in Danish) are added to the sentences. In other words, the semantic contrast is neutralized when a syntactic violation is added. Christensen et al. (2013) investigated long wh-movement in Danish. When the matrix verb was parsed, the fronted wh-phrase could temporarily be interpreted as an argument of this verb (Which school did the man know__ that he should attend__?). In sentences in which the wh-phrase was plausible as an argument of the matrix verb, a higher acceptability score was found, as compared with sentences in which the wh-phrase was implausible as an argument of the matrix verb. This pragmatic effect disappeared in $w h$-island contexts (considered ungrammatical in Danish). Again, we see that when syntactic processing is challenged in some way, pragmatic effects get neutralized.

The neutralization of givenness in long-before-short sentences found in Experiment 2 suggests that complexity is ranked higher, or is more fundamental, than givenness. We suggest that this is linked to the fundamental role of syntax in processing. We have found that reducing comprehension to a reflex of distribution patterns is too simplistic (and at odds with various findings), but even if a production account like the PDC is adopted, complexity still must be ranked higher than givenness in order to explain why the production principle easy first always prefers short-beforelong, but readily ignores givenness in the PP construction 
(in which new-given is marginally preferred). Irrespective of whether the explanation for the neutralization of givenness in long-before-short orders ultimately turns out to be based in production or comprehension, we hope that we have shown the importance of exploring the relative strengths of the different factors affecting word order. Complexity and givenness often align, because short elements are often given, but when they do point in different directions, complexity turns out to be dominant. Similarly, we suggest, when information-structural and parsing constraints point in different directions, parsing takes precedence.

Author note The research reported in this article was financed in part by a grant from the Danish Ministry of Science, Technology and Innovation. The authors wish to thank Søren Feodor Nielsen and Michael Krabbe Borregaard for advice on statistics, Satine Buch Rosenørn von Gersdorff for help collecting the data, and two anonymous reviewers for insightful comments on a previous version of the article.

\section{References}

Arnold, J. E., Wasow, T., Losongco, A., \& Ginstrom, R. (2000). Heaviness vs. newness: The effects of structural complexity and discourse status on constituent ordering. Language, 76, 28-55.

Baayen, R. H. (2011). LanguageR (R package). Retrieved from http:// CRAN.R-project.org/package=language $R$

Baayen, R. H., Davidson, D. J., \& Bates, D. M. (2008). Mixed-effects modeling with crossed random effects for subjects and items. Journal of Memory and Language, 59, 390-412. doi:10.1016/ j.jml.2007.12.005

Bartoń, K. (2009). MuMIn: Multi-model inference (R package, version 0.12.2). Retrieved from http://r-forge.r-project.org/projects/mumin/

Bates, D., Maechler, M., \& Bolker, B. (2011). lme4: Linear mixedeffects models using S4 classes (R package version 0.999375-42). Retrieved from http://CRAN.R-project.org/package=lme4

Bornkessel, I., Schlesewsky, M., \& Friederici, A. D. (2002). Grammar overrides frequency: Evidence from the online processing of flexible word order. Cognition, 85, B21-B30.

Branigan, H. (2007). Syntactic priming. Language and Linguistics Compass, 1, 1-16.

Bresnan, J., Cueni, A., Nikitina, T., \& Baayen, R. H. (2007). Predicting the dative alternation. In G. Bouma, I. Kraemer, \& J. Zwarts (Eds.), Cognitive foundations of interpretation (pp. 265-321). Amsterdam, The Netherlands: Royal Netherlands Academy of Arts and Sciences.

Bresnan, J., \& Hay, J. (2008). Gradient Grammar: An effect of animacy on the syntax of give in New Zealand and American English. Lingua, 118, 245-259.

Brown, M., Savova, V., \& Gibson, E. (2012). Syntax encodes information structure: Evidence from on-line reading comprehension. Journal of Memory and Language, 66, 194-209.

Christensen, K., Kizach, J., \& Nyvad, A. M. (2013). Escape from the island. Grammaticality and (reduced) acceptability of wh-island violations in Danish. Journal of Psycholinguistic Research, 42, $51-70$.

Clifton, C., Jr., \& Frazier, L. (2004). Should given information come before new? Yes and no. Memory \& Cognition, 32, 886-895. doi:10.3758/BF03196867
Clifton, C., Jr., \& Staub, A. (2008). Parallelism and competition in syntactic ambiguity resolution. Language and Linguistics Compass, 2, 234-250.

Coyle, J. M., \& Kaschak, M. P. (2012). Female fertility affects men's linguistic choices. PLOS ONE, 7, e27971. doi:10.1371/journal. pone.0027971

Ferreira, F., \& Clifton, C., Jr. (1986). The independence of syntactic processing. Journal of Memory and Language, 25, 348-368.

Fodor, J. D., \& Inoue, A. (1998). Attach anyway. In J. D. Fodor \& F. Ferreira (Eds.), Reanalysis in Sentence Processing (pp. 101-141). Amsterdam, The Netherlands: Kluwer.

Forster, K. I., \& Forster, J. C. (2003). DMDX: A Windows display program with millisecond accuracy. Behavior Research Methods, Instruments, \& Computers, 35, 116-124. doi:10.3758/BF03195503

Frazier, L. (1987). Sentence processing: A tutorial review. In M. Coltheart (Ed.), Attention and performance XII (pp. 559-586). Hillsdale, NJ: Erlbaum.

Frazier, L., \& Clifton, C., Jr. (1996). Construal. Cambridge, MA: MIT Press.

Givón, T. (1988). The pragmatics of word order: Predictability, importance and attention. In M. Hammond, E. E. Moravcsik, \& J. R. Wirth (Eds.), Studies in syntactic typology (pp. 243-284). Amsterdam, The Netherlands: Benjamins.

Gries, S. T. (2003). Multifactorial analysis in corpus linguistics: A study of particle placement. New York, NY: Continuum.

Hawkins, J. A. (1994). A performance theory of order and constituency. Cambridge, UK: Cambridge University Press.

Hawkins, J. A. (1998). A processing approach to word order in Danish. Acta Linguistica Hafniensia, 30, 63-130.

Hawkins, J. A. (2000). The relative order of prepositional phrases in English: Going beyond manner-place-time. Language Variation and Change, 11, 231-266.

Hawkins, J. A. (2004). Efficiency and complexity in grammars. Oxford, UK: Oxford University Press.

Kiss, K. E. (2007). Topic and focus: two structural positions associated with logical functions in the left periphery of the Hungarian sentence. In C. Féry, G. Fanselow, \& M. Krifka (Eds.), Interdisciplinary studies on information structure 6 (pp. 69-81). Potsdam, Germany: Potsdam University Press.

Kizach, J. (2012). Evidence for weight effects in Russian. Russian Linguistics, 36, 251-270.

Kizach, J., \& Christensen, K. (in press). Ikonicitet og rækkefølge i dansk. In I. S. Hansen \& P. Widell (Eds.), 14. Møde om Udforskningen af Dansk Sprog. Aarhus. Denmark: Aarhus University Press.

Luka, B. J., \& Barsalou, L. W. (2005). Structural facilitation: Mere exposure effects for grammatical acceptability as evidence for syntactic priming in comprehension. Journal of Memory and Language, 52, 436-459.

Macdonald, M. C. (2012). How language production shapes language form and comprehension. Frontiers in Psychology, 4, 226. doi:10.3389/fpsyg.2013.00226

Mitchell, D. C. (1987). Lexical guidance in human parsing: locus and processing characteristics. In M. Coltheart (Ed.), Attention and performance XII (pp. 601-618). Hillsdale, NJ: Erlbaum.

Newmeyer, F. J. (1998). Language form and language function. Cambridge, MA: MIT Press.

Pickering, M. J., \& Garrod, S. (2007). Do people use language production to make predictions during comprehension? Trends in Cognitive Sciences, 11, 105-110.

Pickering, M. J., \& Traxler, M. J. (2003). Evidence against the use of subcategorisation frequency in the processing of unbounded dependencies. Language and Cognitive Processes, 18, 469-503.

Pickering, M. J., Traxler, M. J., \& Crocker, M. W. (2000). Ambiguity resolution in sentence processing: evidence against frequencybased accounts. Journal of Memory and Language, 43, 447-475. 
Poulsen, M. (2008). Acceptability and processing of longdistance dependencies in Danish. Nordic Journal of Linguistics, $31,73-107$.

Prince, E. (1992). The ZPG letter: Subjects, definiteness and information status. In S. Thompson \& W. Mann (Eds.), Discourse description: Diverse analyses of a fundraising text (pp. 295-325). Amsterdam, The Netherlands: Benjamins.

Pritchett, B. L. (1992). Grammatical competence and parsing performance. Chicago, IL: University of Chicago Press.

R Development Core Team. (2009). R: A language and environment for statistical computing. Vienna, Austria: R Foundation for Statistical Computing. ISBN 3-900051-07-0. Retrieved from www.R-project.org

Schwarzschild, R. (1999). Givenness, avoidf and other constraints on the placement of accent. Natural Language Semantics, 7, 141-177.

Sgall, P., Hajičová, E., \& Panevová, J. (1986). The meaning of the sentence in its semantic and pragmatic aspects. Prague, Czech Republic: Reidel.

Smith, N. J., \& Levy, R. (in press). The effect of word predictability on reading time is logarithmic. Cognition.

Snyder, W. (2000). An experimental investigation of syntactic satiation effects. Linguistic Inquiry, 31, 575-582.

Sprouse, J. (2007). Continuous acceptability, categorical grammaticality, and experimental syntax. Biolinguistics, 1, 123-134.

Staub, A. (2007). The parser doesn't ignore transitivity, after all. Journal of Experimental Psychology: Learning, Memory, and Cognition, 33, 550-569.
Szmrecsányi, B. M. (2004). On operationalizing syntactic complexity. In G. Purnelle, C. Fairon, \& A. Dister (Eds.), Le poids des mots: Proceedings of the 7th International Conference on Textual Data Statistical Analysis. Louvain-la-Neuve, March 10-12 (pp. 10321039). Louvain-la-Neuve, France: Presses universitaires de Louvain.

Togeby, O. (2003). Fungerer denne saetning? Funktionel dansk sproglcere. Copenhagen, Denmark: Gad.

van Gompel, R. P. G., \& Pickering, M. J. (2001). Lexical guidance in sentence processing: A note on Adams, Clifton, and Mitchell (1998). Psychonomic Bulletin \& Review, 8, 851-857. doi:10.3758/ BF03196228

Vikner, S. (1995). Verb movement and expletive subjects in the Germanic languages. Oxford, UK: Oxford University Press.

Wagenmakers, E.-J., \& Farrell, S. (2004). AIC model selection using Akaike weights. Psychonomic Bulletin \& Review, 11, 192-196. doi:10.3758/BF03206482

Wasow, T. (1997). Remarks on grammatical weight. Language Variation and Change, 9, 81-105. doi:10.1017/S0954394500001800

Wasow, T. (2002). Postverbal behavior. Stanford, CA: CSLI Publications.

Wasow, T., \& Arnold, J. (2003). Post-verbal constituent ordering in English. In G. Rohdenburg \& B. Mondorf (Eds.), Determinants of grammatical variation in English (pp. 119-154). Dordrecht, The Netherlands: Mouton.

Wiechmann, D., \& Lohmann, A. (2013). Domain minimization and beyond: Modeling prepositional phrase ordering. Language Variation and Change, 25, 65-88. doi:10.1017/S0954394512000233 